\title{
Strand-specific RNA sequencing reveals extensive regulated long antisense transcripts that are conserved across yeast species
}

\author{
Moran Yassour ${ }^{1,2,3}$, Jenna Pfiffner ${ }^{1 \dagger}$, Joshua Z Levin ${ }^{1 \dagger}$, Xian Adiconis ${ }^{1}$, Andreas Gnirke ${ }^{1}$, Chad Nusbaum, \\ Dawn-Anne Thompson ${ }^{1 *}$, Nir Friedman ${ }^{3,4^{*}}$, Aviv Regev ${ }^{1,2^{*}}$
}

\begin{abstract}
Background: Recent studies in budding yeast have shown that antisense transcription occurs at many loci. However, the functional role of antisense transcripts has been demonstrated only in a few cases and it has been suggested that most antisense transcripts may result from promiscuous bi-directional transcription in a dense genome.

Results: Here, we use strand-specific RNA sequencing to study anti-sense transcription in Saccharomyces cerevisiae We detect 1,103 putative antisense transcripts expressed in mid-log phase growth, ranging from 39 short transcripts covering only the $3^{\prime}$ UTR of sense genes to 145 long transcripts covering the entire sense open reading frame. Many of these antisense transcripts overlap sense genes that are repressed in mid-log phase and are important in stationary phase, stress response, or meiosis. We validate the differential regulation of 67 antisense transcripts and their sense targets in relevant conditions, including nutrient limitation and environmental stresses. Moreover, we show that several antisense transcripts and, in some cases, their differential expression have been conserved across five species of yeast spanning 150 million years of evolution. Divergence in the regulation of antisense transcripts to two respiratory genes coincides with the evolution of respiro-fermentation.
\end{abstract}

Conclusions: Our work provides support for a global and conserved role for antisense transcription in yeast gene regulation.

\section{Background}

Antisense transcription plays an important role in gene regulation from bacteria to humans. While the role of antisense transcripts is increasingly studied in metazoans [1], less is known about its relevance for gene regulation in the yeast Saccharomyces cerevisiae, a key model for eukaryotic gene regulation. Recent genomic studies using tiling microarrays showed evidence of stable antisense transcription in S. cerevisiae [2,3] and Schizosaccharomyces pombe $[4,5]$.

\footnotetext{
*Correspondence: dawnt@broadinstitute.org; nir@cs.huji.ac.il; aregev@broadinstitute.org

+ Contributed equally

${ }^{1}$ Broad Institute of MIT and Harvard, 7 Cambridge Center, Cambridge, MA 02142, USA

${ }^{3}$ School of Engineering and Computer Science, Hebrew University, Ross Building, Givat Ram Campus, Jerusalem, 91904, Israel

Full list of author information is available at the end of the article
}

It is unclear how broad the role of antisense transcription is and what key functional processes in yeast it affects. A few functional antisense transcripts have been implicated in the control of several key genes, including the meiosis regulator gene IME4 [6], the phosphate metabolism gene $\mathrm{PHO} 4$ [7], the galactose metabolism gene GAL10 [8], and the inositol phosphate biosynthetic gene KCS1 [9]. In contrast, genome-scale analysis in yeast suggested that antisense transcripts largely arise from bi-directional, possibly promiscuous, transcription from nucleosome free regions in promoters or $3^{\prime}$ UTRs of upstream protein coding genes [2,3]. The ability to massively sequence cDNA libraries (RNA-seq) can facilitate the discovery of novel transcripts [10-12], but most studies have not distinguished the transcribed strand.

Here, we used massively parallel sequencing to sequence a strand-specific cDNA library from RNA isolated from S. cerevisiae cells at mid-log phase. We

\section{() Biomed Central}


found 1,103 putative antisense transcripts in those cells, ranging from short ones that cover only the 3' UTR of sense genes to over a hundred long ones that cover the entire sense ORF. Many of the putative sense targets encode proteins with important roles in stationary phase, stress responses, or meiosis. We validated the differential regulation of 67 antisense transcripts and their sense targets in conditions ranging from nutrient limitation to stress, and show that the exosome component Rrp6 affects their levels, but that the histone deacetylase Hda 2 does not. Furthermore, for a few examples we show that antisense transcripts and their differential regulation are conserved over 150 million years across five yeast species. Our results support a potential conserved role for antisense transcription in yeast gene regulation.

\section{Results}

\section{Strand-specific RNA-seq of S. cerevisiae cells}

To identify antisense transcripts in yeast, we used massively parallel sequencing (Illumina) to sequence a strand-specific cDNA library from $S$. cerevisiae during mid-log growth in rich media. The approach we used [13] relies on the incorporation of deoxy-UTP during the second strand synthesis, allowing subsequent selective destruction of this strand (Materials and methods). Our sequencing yielded 9.22 million 76-nucleotide paired-end reads that map to unique positions in the genome.

Of the reads that map to regions with a known annotation for uni-directional transcription (from the Saccharomyces Genome Database (SGD) [14]), only $0.62 \%$ were mapped to the opposite (antisense) strand, demonstrating the strand-specificity of our library [15] (Materials and methods). We next combined these reads to define consecutive regions of strand-specific transcription (Materials and methods), and found 8,778 units, covering 4,944 of the 5,501 (90\%) genes expressed in this condition (top 85\% [12]) at the correct orientation, for at least $80 \%$ of the length of each gene (Materials and methods; Additional files 1 and 2).

\section{Identification of 1,103 antisense transcripts that vary in sense coverage from the $3^{\prime}$ UTR to the entire ORF}

We found 1,103 putative units that have an antisense orientation relative to annotated transcripts and cover at least $25 \%$ of a known transcript on the opposite strand, using published UTR estimates [2] (Materials and methods; Additional file 1). While antisense reads are only a small minority $(0.62 \%)$ of the total reads, they aggregate in a relatively small number of loci, with $62 \%$ of the antisense reads concentrated in the 1,103 units we defined. The remaining $38 \%$ are mostly isolated reads scattered across the genome (Figure S1 in Additional file 3).
We observe a range of antisense unit lengths (Figure S2 in Additional file 3). At one extreme are 39 units that cover at least $25 \%$ of the transcript but none of the ORF, most commonly at the 3' UTR (for example, Unit3689, a putative antisense transcript to NOP10; Figure 1a). Other units cover a substantial portion of the sense ORF. For example, 438 units overlap with at least $50 \%$ of the sense ORF, and 145 units cover the entire sense ORF (for example, Unit4966, a putative antisense to the $M B R 1$ gene; Figure 1b). In some cases a single sense gene may be covered by more than one antisense unit, most likely due to low antisense expression levels that result in gaps in coverage (for example, Unit8753, Unit8754, Unit8756 and Unit8758 all opposite to the OPT2 gene; Figure S3 in Additional file 3). To avoid spurious or 'gapped' calls by our automatic method, we manually inspected each of the units, and focused on the 402 units that passed manual inspection and overlap at least $75 \%$ of a sense ORF (Materials and methods).

The 402 antisense units are supported by several lines of evidence. First, comparing the units to published data from strand-specific tiling arrays [2], we find that 143 of our 402 units $(36 \%)$ are at least $80 \%$ covered by stable antisense units as previously defined [2], while 224 units were not detected at all on tiling arrays (Additional file 1; Materials and methods). Finally, 336 of the 402 units are supported by an independent RNA-seq experiment we conducted using an RNA ligation protocol [16] for strand-specific library preparation (Materials and methods) [15]. The lower number of units detected using the independent library reflects the less continuous nature of the data collected by the alternative protocol [15].

\section{Antisense units are unlikely to result solely from leaky transcription}

We next assessed the previously suggested possibility $[2,17]$ that antisense transcription is a consequence of leaky transcriptional regulation, through either unterminated transcription, bi-directional transcription initiation from promoters, or transcription from potential nucleosome-free regions (NFRs) in $3^{\prime}$ UTRs. We found that 48 and 27 units might reside within a long $3^{\prime}$ or $5^{\prime}$ UTR, respectively. Of the remaining 333 antisense units, 149 appear to share the (divergent) promoter of a known neighbor transcript, consistent with previous reports $[2,3]$. An additional 43 units may be transcribed from potential NFRs in the $3^{\prime}$ UTR of an adjacent transcript [18]. The remaining 141 units (35\%) cannot be accounted for by transcription from a known promoter or 3' UTR (when considering 400-bp margins; Figure S4 in Additional file 3).

We compared the change in expression of antisense units and such neighboring genes between cells grown in rich media containing glucose (yeast peptone dextrose 
(a)

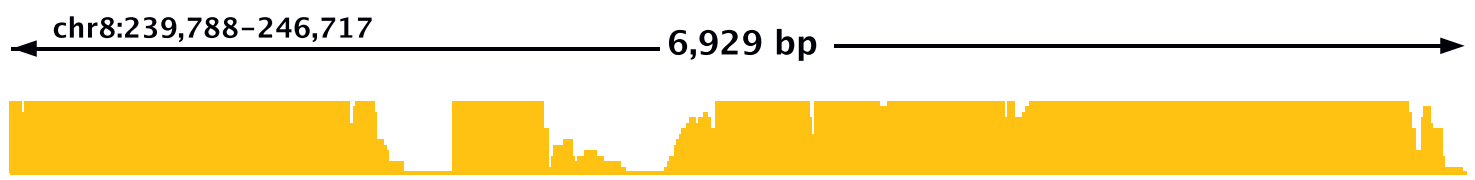

Forward

reads

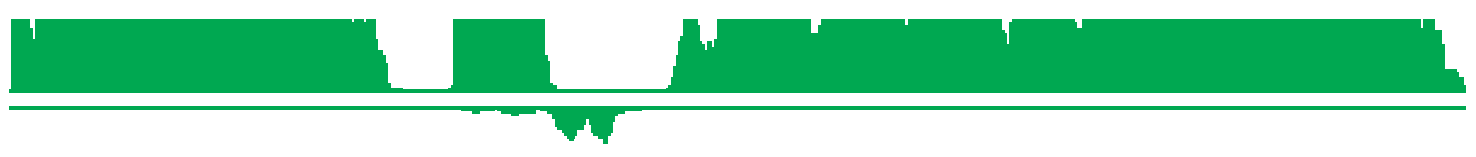

Reverse

reads

Raw

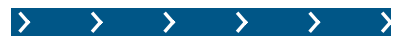

Unit3687

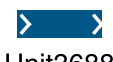

Unit3688

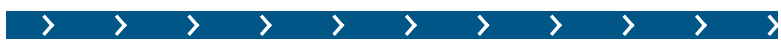

units

Unit3689

SGD

$\underset{\text { ERG7 }}{\langle>>>>} \underset{\text { NOP10 }}{>>1}$

Unit3689

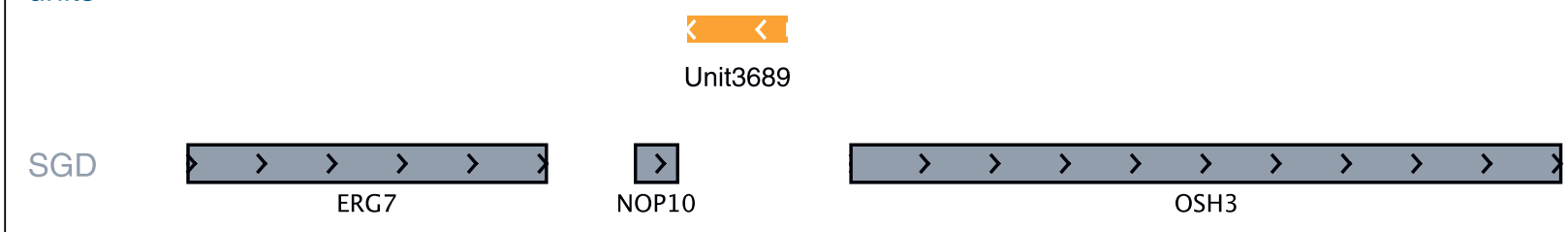

(b)

\section{CDNA}

reads

Forward

reads

Reverse

reads

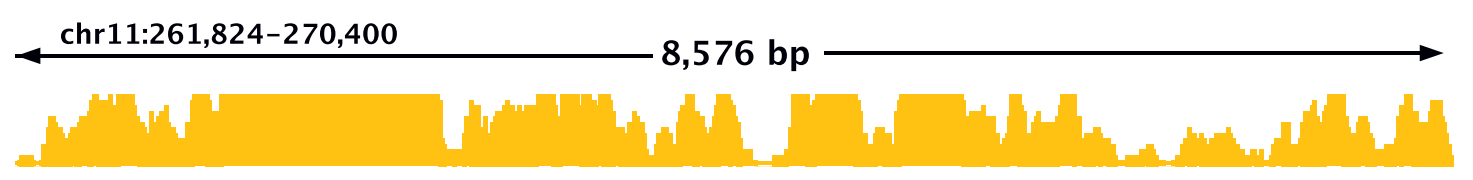

Raw
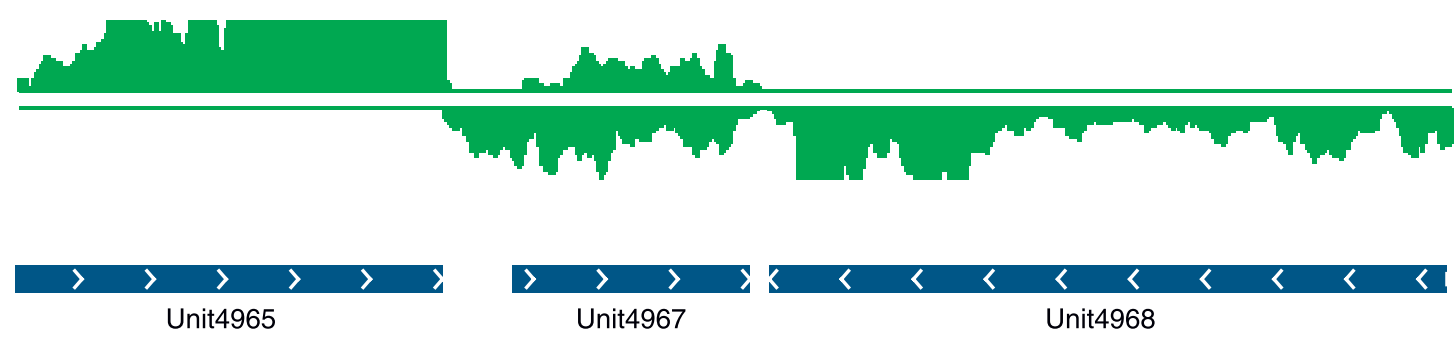

Manual

units

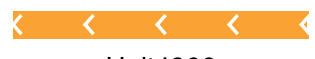

Unit4966

SGD

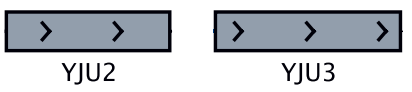

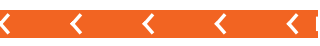

ManualUnit225

Figure 1 Strand-specific RNA-seq identifies 1,103 antisense units associated with stationary phase, stress, and meiosis genes in

S. cerevisiae. (a) Typical short antisense (Unit3689, antisense to NOP10). Shown are reads mapped from a standard CDNA sequencing library [15] (yellow), and from the strand-specific library prepared and run side-by-side on the same flow cell (green: forward reads above, reverse reads below). All coverage tracks were normalized to the total number of reads mapped, and are shown up to a threshold of $3 \times 10^{-8}$ of total mapped reads (genome-wide). Units were called from the strand-specific library (blue units, known genes; orange, putative antisense), and are shown along with the manually curated units (red) and the known gene annotations from the SGD (gray). (b) Typical long antisense

(ManualUnit225, antisense to MBR1). Tracks are as in (a). The figures are shown using the Integrative Genome Viewer [36]. 
(YPD)) and ethanol (yeast peptone ethanol (YPE)) as the main carbon source [2]. We reasoned that 'leaky transcription' would result in strong positive correlation in expression between the antisense transcript and the neighboring gene. However, we found a very low correlation $\left(R^{2}=0.07\right.$; Figure S5 in Additional file 3), suggesting only weak co-regulation through leaky transcription, from divergent promoters or $3^{\prime}$ NFRs, if at all. Thus, even among the units that could hypothetically arise from leaky transcription, there is little if any evidence of such events.

We also examined the hypothesis that antisense is transcribed to prevent the neighboring gene from runthrough transcription. Of the 402 units, 72 (18\%) end relatively close $(<200 \mathrm{bp})$ to the 3 ' ends of known genes (for example, Unit3689 ends close to the NOP10 gene shown in Figure 1a). On average, the 3' UTRs of these 72 genes are shorter than those of other genes $(P<$ 0.0058, Wilcoxon test; Figure S6 in Additional file 3). This minority of units could thus potentially play a role in curbing runthrough transcription.

\section{Stress, meiosis and nutrient limitation genes are associated with antisense transcripts at mid-log phase}

To explore the potential function of the antisense units, we examined the known function and expression pattern of their associated sense transcripts. We found that the set of ORFs with $75 \%$ or more antisense coverage is enriched for genes induced after the diauxic shift $(P<6$ $\left.\times 10^{-14}\right)$ or in stationary phase $\left(P<2 \times 10^{-10}\right)$, during stress $\left(P<2 \times 10^{-27}\right)$, and in some meiosis and sporulation experiments (for example, 85 of 805 genes induced at $8 \mathrm{~h}$ in a sporulation time course, $P<3 \times 10^{-6}$ ), and include multiple central genes in these processes. For example, the genes encoding the key meiosis proteins IME4, NDT80, REC102, GAS2, SPS19, SLZ1, RIM9, and $S M K 1$ are all associated with long antisense transcription. This is consistent with previous studies in $S$. pombe [4] showing a preponderance of antisense transcription in genes induced during meiosis. Long antisense is also found in many key respiration and mitochondrial genes, including $H A P 3, C O X 8, C Y B 2$, CYC3, COX5B, MMF1, NCA3, CYC1, MBR1, PET10, $C O X 12$, and $A T P 14$. Genes from other processes repressed during mid-log phase are also associated with long antisense transcripts. Notably, these include at least five members of the PHO regulon (VTC1, PHO5, PHM8, ICS2, PHO3) and three genes from the GAL regulon (GAL4, GAL10, GAL2). This suggests that antisense regulation may be prevalent across these regulons rather than at single target genes (as found in [6-8]). Furthermore, the expression of 149 of the antisense transcripts is inversely related to that of their sense targets, as measured on tiling arrays [2] in several conditions (glucose versus ethanol, versus galactose, and in $\Delta$ rrp6; Figure S7 in Additional file 3). Certain key genes that are highly expressed in mid-log phase are also associated with detectable transcription of long antisense units. These include some of the ribosomal protein genes (for example, RPS26A, RPS20), glycolytic enzymes (for example, $C D C 19, P G K 1$ ), and cell cycle regulators (for example, PCL2, APC11, ASK1). Nevertheless, these observations suggest that antisense transcription may be regulated in a condition-specific manner in S. cerevisiae and may be involved in the repression of stress, stationary phase and meiosis genes in rich growth conditions.

\section{Differential regulation of antisense-sense pairs in nutrient limitation and stress}

To test this hypothesis, we first experimentally measured the existence and differential expression of nine pairs of sense and antisense transcripts in S. cerevisiae, where the sense gene was known to be induced and important in stress or stationary phase states. We used strand-specific RT-PCR (Materials and methods) followed by sequencing to check for the presence of each sense and antisense transcript in mid-log (rich media), and found that all of the nine tested antisense units were present as expected (Additional file 4). Next, we used strand-specific quantitative real-time PCR (qRTPCR; Materials and methods) to quantify the differential expression of six sense and antisense transcript pairs between mid-log and early stationary phase. We found that all six of the pairs were differentially expressed, with induction of the sense accompanied by repression of the antisense (Figure 2a; Additional file 5). Third, we devised a novel assay based on the nCounter technology for sensitive multiplex measurement of mRNAs $[19,20]$ (Materials and methods) to measure the absolute level of expression of the nine pairs across five conditions, including mid-log, early stationary phase, stationary phase, high salt and heat shock. We found that the gene pairs exhibited inverse transcription patterns across all the tested conditions (Figure 2b). The differential expression we observed is consistent with antisense interference with sense expression (Figure 2b; Additional file 6), and with the known function and regulation of the sense genes. These included proteins with roles in respiration and mitochondria (PET1O and MBR1 $[21,22])$, repression of ribosomal protein gene expression in stress and poor nutrients (CRF1 [23]), and the response to caloric restriction (CTA1 [24]). Thus, differentially regulated antisense transcription may play a role in the distinction between mid-log non-stress growth and stationary phase and stress conditions in $S$. cerevisiae.

Finally, to test the generality of these suggestive patterns, we expanded the nCounter assay to measure the 
(a)

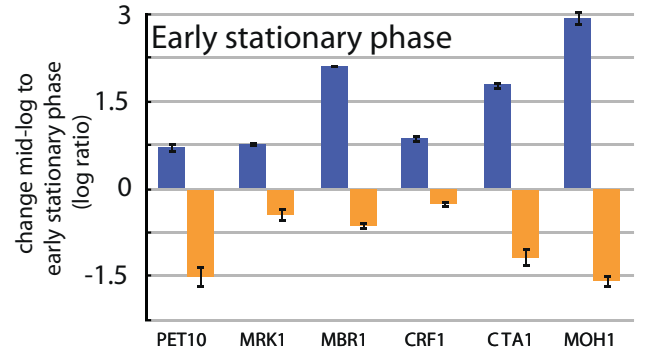

(b)
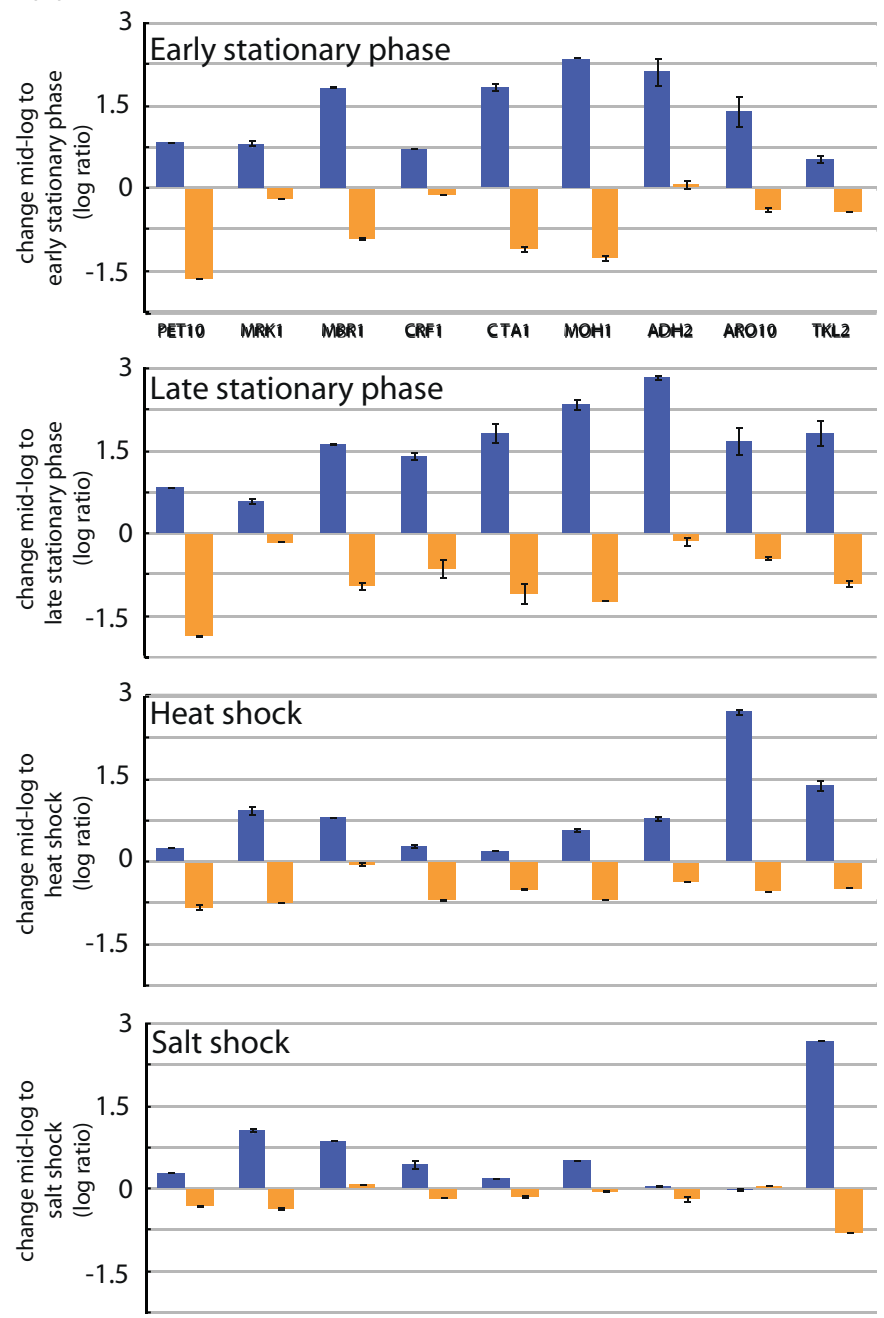

(c)

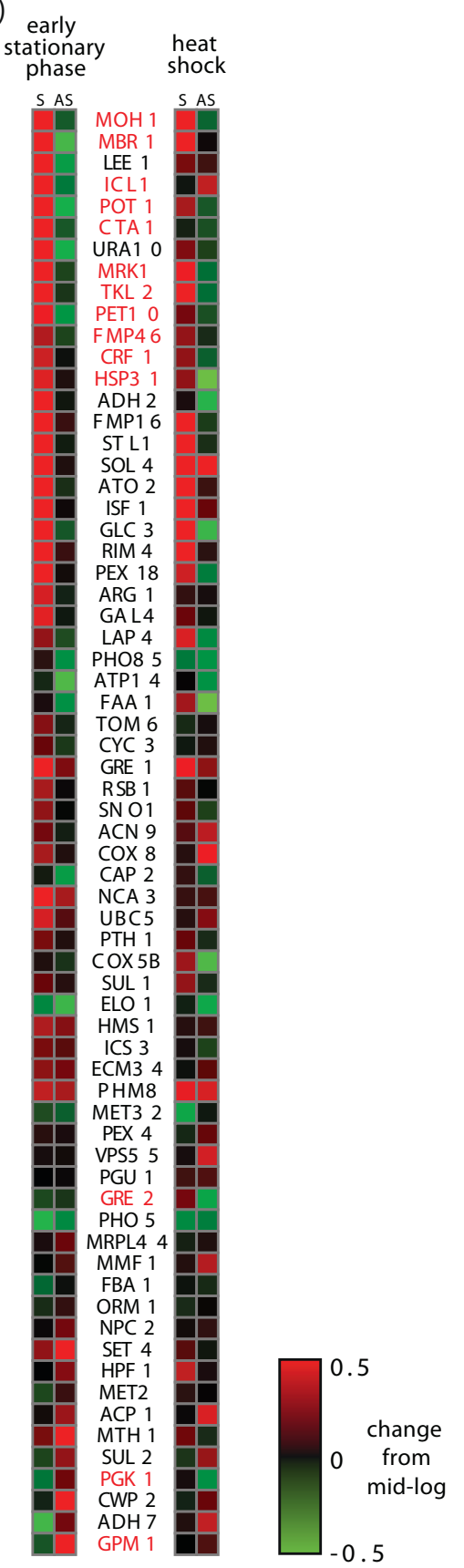

Figure 2 Quantitative expression measurements of putative antisense units and the corresponding sense genes in S. cerevisiae (a) Strand-specific qRT-PCR measurements of six pairs of known sense genes and their putative antisense units in comparing mid-log and early stationary phase (the $y$-axis shows the $\log _{2}$ ratio of expression in early stationary phase versus mid-log). Error bars indicate the standard deviation between biological replicates and different primers. (b) nCounter [20] measurements of nine representative putative antisense units, comparing mid-log to early stationary phase, stationary phase, heat shock and salt stress (the $y$-axis is as in (a) for the examined condition). Error bars indicate the standard deviation between biological replicates. (c) nCounter measurement for 67 tested sense-antisense pairs in early stationary phase (left) and heat shock (right), each relative to a mid-log (no stress) control. The columns marked ' $S$ ' and ' $A$ ' represent the sense and antisense change, respectively. Red, induced; green, repressed; black, no change. The names of genes highlighted in the main text are shown in red. 
expression of 67 sense-antisense pairs in log-phase, early stationary phase, and after 15 minutes under heat shock conditions (Figure 2c; Additional file 6). We found 25 pairs where the sense was induced while the antisense was repressed in either early stationary phase or heat shock (12 in early stationary phase, 21 in heat shock, 8 in both), and 12 pairs where the sense was repressed while the antisense was induced (6 in early stationary phase, 8 in heat shock, 2 in both). Notably, 17 of the 25 pairs with induced sense and repressed antisense in early stationary phase (relative to mid-log) involved sense genes important in respiration, mitochondrial function, alternative carbon source metabolism and starvation response (for example, PET10, MBR1, FMP46, POT1, MOH1, TKL2, ICL1, CTA1). Conversely, four of the six pairs with the opposite pattern involved sense genes with key roles in glycolysis and fermentation (for example, GPM1, PGK1). Many of the pairs with induced sense and repressed antisense following heat shock overlapped with those responsive to early stationary phase (consistent with known metabolic changes under stress [25]). Furthermore, they also included four genes known to be important under environmental stresses (the regulators CRF1 and MRK1, and the effectors HSP31 and GRE2). Thus, antisense regulation may play a regulatory role at coordinating the major metabolic changes in the diauxic shift and early stationary phase, and some of the changes in the environmental stress response [21-24].

\section{The exosome component Rrp6 affects antisense levels, but the histone deacetylase $\mathrm{Hda} 2$ does not}

To explore the mechanistic regulation of antisense transcription, we measured the expression of the 67 pairs of sense and antisense units using the nCounter assay in strains deleted for the exosome component RRP6 $(\Delta r r p 6)$, the histone deacetylase HDA2 $(\Delta h d a 2)$, or both ( $\Delta r r p 6 \Delta h d a 2)$. Previous studies [2,7] have suggested that $\Delta$ rrp6 increases the levels of antisense transcription in the PHO84 locus, and that Hda2 is required for mediating the effect of antisense transcription on the sense transcripts in this locus. If these findings apply more broadly, we expect higher levels of antisense transcripts in $\Delta r r p 6$, and a change in the relative levels of sense to antisense in either the $\Delta h d a 2$ or $\Delta r r p 6 \Delta h d a 2$ strains.

We found increased transcription of the antisense units in the $\Delta \operatorname{rrp} 6$ mutant, with a mild reduction of the sense transcripts $(R=-0.36$; Figure 3a,c; Figure S8a in Additional file 3 ). This is consistent with regulation of antisense transcript levels by the exosome, and with a possible, albeit mild, effect of this increase in antisense on reduction in the level of sense transcripts. We found only a very mild, if any, effect on either sense or antisense transcripts levels in $\Delta h d a 2$ (Figure $3 \mathrm{~b}$; Figure S8b in Additional file 3), suggesting that $\mathrm{Hda} 2$ plays at most a very minor independent role in the regulation of our transcripts. We also found no evidence for a synergistic effect between the mechanisms, since transcript levels in the double mutant were very close to those in $\Delta \operatorname{rrp} 6$ (Figure S8c in Additional file 3). Finally, the differential expression of the sense genes between conditions was not substantially affected in any of these mutants (for example, $R>0.93$ in all conditions; Figure 3d; Figure S9 in Additional file 3), suggesting that relative regulation itself was not compromised in any of these mutants. This may be due to a comparable effect of the deletion in all conditions. Thus, the mechanistic basis of senseantisense regulation involved Rrp6, but may be more complex than that in the simple model suggested for PHO84 [7].

\section{Evolutionary conservation of six antisense transcripts and their regulation in five species of yeast}

Finally, we tested whether the presence and regulation of antisense transcripts is conserved in five other species of yeast. We reasoned that while the biochemical function and mechanistic basis of each antisense unit may be distinct or complex, their conservation would provide additional support for their functional and ancestral role in gene regulation. We chose five species with diverse lifestyles and a broad phylogenetic range spanning approximately 150 million years (Figure 4). These include three sensu stricto Saccharomyces species ( $S$. paradoxus, S. mikatae, $S$. bayanus), a more distant species that diverged after the whole genome duplication (WGD; S. castellii), and one species that diverged preWGD (Kluyveromyces lactis). Importantly, post-WGD species are known to follow a respiro-fermentative lifestyle, repressing the expression of respiration genes (for example, PET10) in mid-log phase, whereas pre-WGD species follow a respirative lifestyle without such repression. We used conserved synteny and gene orthology of $S$. cerevisiae loci $[26,27]$ to identify orthologous regions for candidate antisense transcription in the five species. We focused on six of the units validated in $S$. cerevisiae (PET10, MRK1, MBR1, CRF1, CTA1, MOH1), used strand-specific RT-PCR and sequencing to validate the presence of the orthologous sense and antisense transcripts in each species in mid-log and early stationary phase, and used strand-specific quantitative real-time PCR to quantify transcript levels (Additional file 5).

We found that the tested antisense units are largely conserved in the sensu stricto species, and less so at increasing evolutionary distances. All six units were detected in at least one species besides $S$. cerevisiae. Five of the six units are present in sensu stricto Saccharomyces, and four are still observed in S. castellii and $K$. lactis. The absence in $K$. lactis of an antisense transcript to the PET10 gene, important for respiratory growth, is 


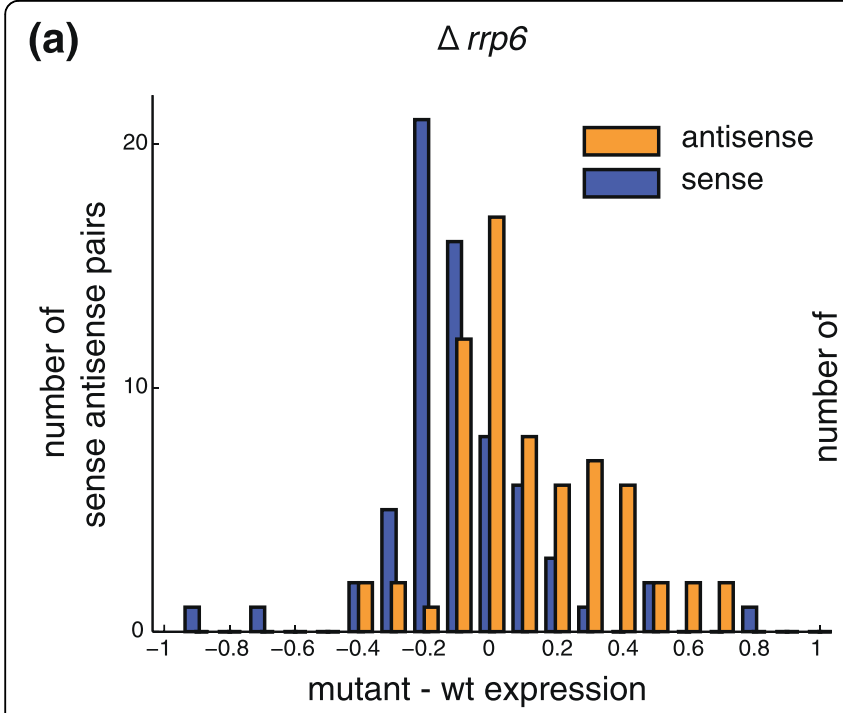

(b) $\quad \Delta$ hda2

(c)

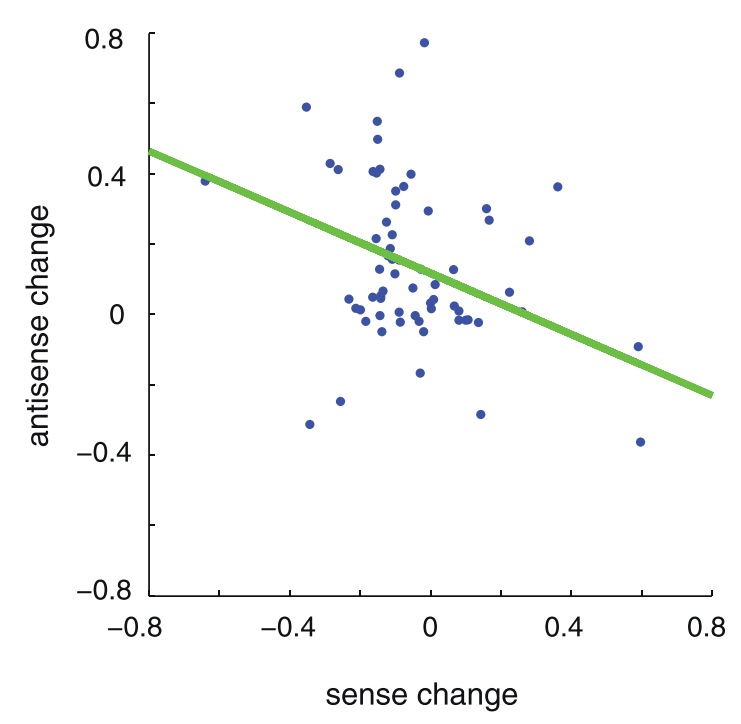

(d)

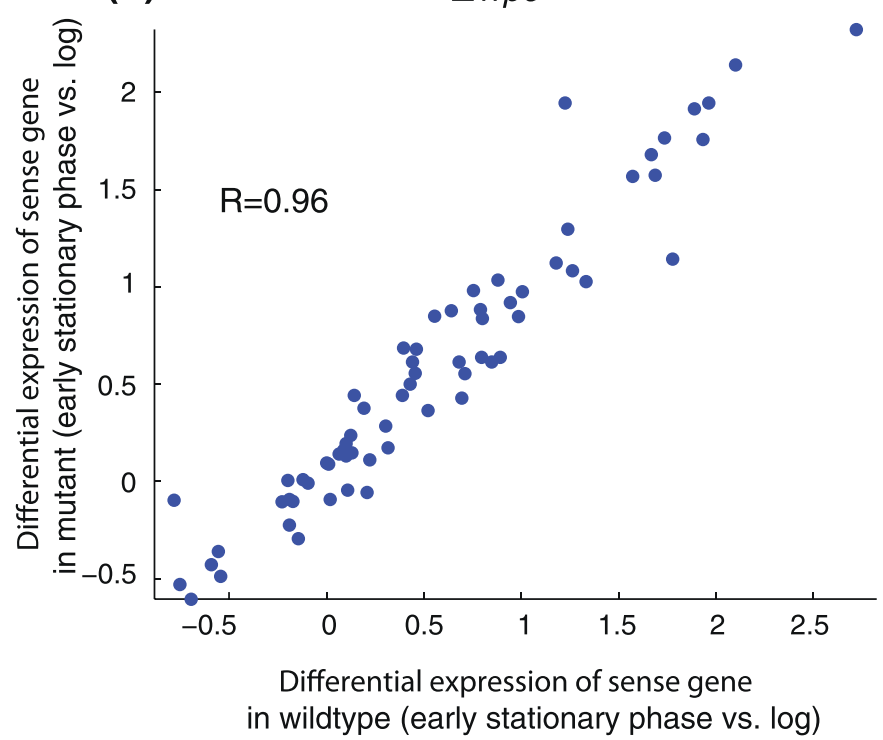

Figure 3 Effect of Rrp6 and Hda2 on antisense transcript levels and sense-antisense regulation. (a,b) The distribution of changes in expression levels ( $\mathrm{x}$-axis) for sense (blue) and antisense (orange) transcripts in the $\Delta r r p 6$ (a) and $\Delta$ hda2 (b) mutants compared to the wild type (wt). In the $\Delta r r p 6$ mutant (a) there is a mild increase in antisense levels and decrease in sense levels. No such changes are observed in the $\Delta h d a 2$ mutant (b). (c) Negative correlation between change in antisense transcript (y-axis) and in sense transcript (x-axis) in the $\Delta r r p 6$ mutant relative to the wild-type strain. (d) Similarity in differential sense gene expression from mid-log to early stationary phase between the wild type ( $x$-axis) and the $\Delta r r p 6$ mutant (y-axis).

consistent with its respiratory lifestyle, and suggests that antisense transcription in this gene may have appeared after the whole genome duplication. We cannot rule out the possibility, however, that other antisense units are present in the $K$. lactis genome, or that the missing antisense units are expressed under different conditions.

The anti-correlation between sense and antisense units observed in S. cerevisiae is conserved in most postWGD species, but not in the pre-WGD $K$. lactis. The differential expression of five sense-antisense pairs (PET10, MRK1, MBR1, CRF1, CTA1) is conserved in at least two out of three other sensu stricto species. The more distant $S$. castellii shows less conservation of transcriptional regulation, most prominently in the PET10 gene. In contrast, although we could detect four of the antisense units in $K$. lactis, their differential expression was not conserved. This is consistent with the lack of repression of the corresponding sense gene in mid-log 


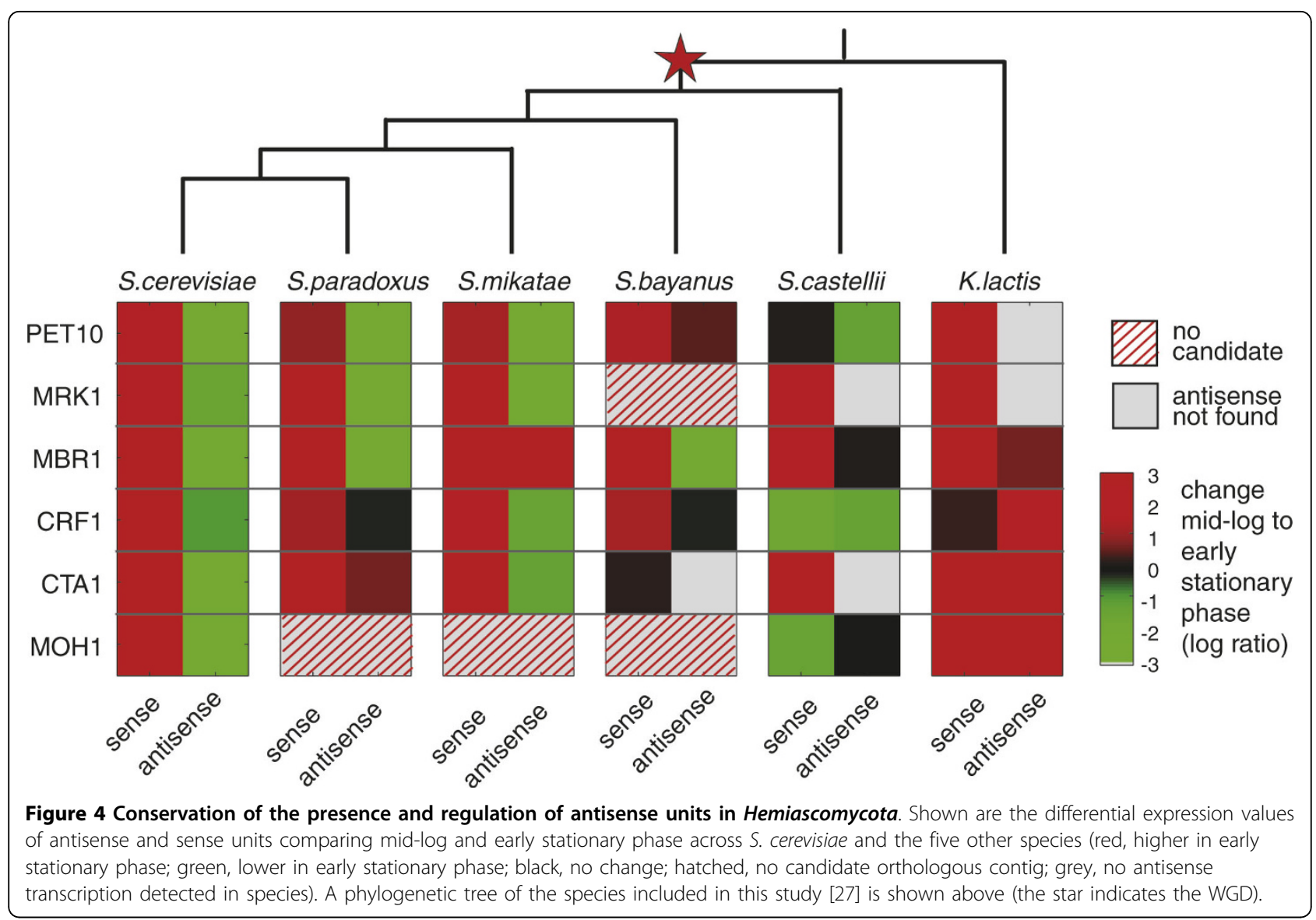

K. lactis cultures. The absence of antisense (for two genes) and the observed correlated (rather than anticorrelated) regulation (for three others) in K. lactis may reflect either the increased phylogenetic distance or may be more directly related to the shift to a respiro-fermentative lifestyle. In the latter case, either antisense transcription or its regulatory pattern in those genes may have evolved concomitantly with the emergence of fermentative growth, and the repression of respiratory genes, such as PET10 and MBR1. Further experiments are needed to elucidate this relationship.

\section{Discussion}

In this study, we used strand-specific mRNA sequencing to explore the extent of antisense transcription in yeast, and found 1,103 putative antisense transcripts expressed in mid-log phase in S. cerevisiae, ranging from 39 short ones covering only the $3^{\prime}$ UTR of sense genes to 145 long ones covering the entire sense ORF. We focus on 402 long antisense units (each spanning over $75 \%$ of a coding unit). In this category, our sequencing based methodology allowed us to identify 224 new antisense transcripts that, in previous studies based on tiling microarrays [2], were either undetected or annotated as long UTRs of neighboring genes.

What could be the role of such prevalent antisense transcription? To date, functional studies have identified a regulatory role for a few antisense transcripts [6-8], whereas genome-wide analyses have suggested that antisense transcripts may represent promiscuous leaky transcription from NFRs at the promoter of a neighboring gene or the $3^{\prime}$ UTR of the sense gene $[2,3,28]$. The diversity of lengths in our 1,103 antisense units - ranging from long antisense units covering entire ORFs to shorter ones mostly at the $3^{\prime}$ UTR - suggests that there may be more than a single underlying mechanism for their formation and function.

Our results do not support promiscuous or aberrant transcription as the primary cause of the observed antisense transcripts. We find antisense transcription at only $18 \%$ of the genes. Moreover, many of the units are long and show robust sequence coverage, in contrast to what we might expect in a noisy process. Finally, antisense genes are only very weakly correlated to their neighbors, inconsistent with leaky transcription from divergent promoters or $3^{\prime}$ NFRs. 
Characterizing the functional effect of each unit requires delicate assays to disable the antisense unit, without harming the sense gene, which have been successfully performed only in a few examples [6-8]. We therefore instead examined whether the changes in expression of sense and antisense are consistent with a regulatory function. We chose to focus on the long antisense units because they exhibit strong signal in our data, are less well-studied, are less likely to reflect noise, and can be verified more rigorously.

We found that the sense transcripts corresponding to longer antisense units are significantly enriched for key processes in S. cerevisiae, including stress response, the differential regulation of growth and stationary phase, and possibly meiosis and sporulation. The high level of antisense expression is consistent with the repression of these processes in fast growing yeast, and suggests a potential global function. Indeed, when we examined the relative change in expression in sense and antisense units across multiple conditions using three technologies (tiling arrays [2], strand-specific qPCR, and nCounter measurements), we found a strong and consistent anti-correlation between sense genes and the corresponding antisense units. While these results are consistent with regulatory function of antisense units (for example, reduction of antisense transcription leads to increased sense transcription), we cannot rule out the possibility that anti-correlation can occur without active regulation of the antisense transcript. For example, it is possible that when a sense gene is repressed, there is a relieved hindrance of antisense-transcription. Notably, we found support for the role of Rrp6 in the regulation of antisense levels, resulting in an increase in antisense levels in the $\Delta r r p 6$ mutant, and a concomitant, albeit very mild, decrease in sense levels. We could not demonstrate a general effect of Hda2 on the levels of sense or antisense transcripts (either alone or together with Rrp6), and - in all mutants - the differential expression of sense and antisense remained highly correlated to the wild-type regulation. This suggests that it may be challenging to generalize the mechanisms shown for specific transcripts (PHO84) to all antisense transcripts.

Independent support for a potential function is the conservation of expression and regulation of six antisense units tested across five species that have diverged more than 150 million years ago, suggesting purifying selection. Notably, previous studies in mammals have shown that certain non-coding RNAs (that are not antisense) can be conserved at the sequence level $[17,29]$, but the applicability of such analyses to antisense transcripts that cover ORFs is limited, and hence experimental data are needed to show conservation. We find that both the presence and the regulation of antisense transcripts are most diverged in the distant, pre-WGD species $K$. lactis. This may reflect either the increased phylogenetic distance per se, or an evolved role in regulating respiration genes in post-WGD species. Another possibility for the lack of conservation in expression or absence of antisense in $S$. castellii and $K$. lactis may be the presence of RNA interference in these species [30]. Further experiments will be needed to elucidate these possibilities and characterize the full functional scope of antisense transcription in yeasts.

\section{Conclusions}

Our results expand and strengthen the existing body of evidence that antisense transcription is a substantial phenomenon in yeast, and not solely a noisy by product of imprecise transcription regulation. While the mechanism and function of antisense transcription is still elusive, our results indicate that antisense transcription is often conserved and plays a regulatory role in the yeast transcriptional response.

\section{Materials and methods \\ Supplementary website}

All tables, figures, raw sequenced reads, and a link to a browser with the mapped reads appear on our supplementary website [31].

\section{Strains and growth conditions}

Strains are listed in Table 1. Cultures were grown in the following rich medium: yeast extract (1.5\%), peptone (1\%), dextrose (2\%), SC Amino Acid mix (Sunrise Science - San Diego, CA, USA) 2 g/l, adenine $100 \mathrm{mg} / \mathrm{l}$, tryptophan $100 \mathrm{mg} / \mathrm{l}$, uracil $100 \mathrm{mg} / \mathrm{l}$, at $200 \mathrm{RPM}$ in a New Brunswick Scientific (Edison, NJ, USA) air-shaker. The medium was chosen to minimize cross-species variation in growth. Following the experimental treatments described below, stressed and mock cultures were transferred to shaking water baths.

To generate strain RGV 69(rrp6A::KANMX6, hda2A:: NatMX4), strain RGV 71(rrp64::KANMX6) was transformed with a PCR product constructed by using the pAG25 containing the NatMX4 cassette using the following primers: GTAAAAGTATTTGGCTTCATTAG TGTGTGAAAAATAAAGAAAATAGATACAATACTATCGACGGTCGACGGATCCCCGGGTT and AAGA AAGTATATAAAATCTCTCTATATTATACAGGCTACTTCTTTTAGGAAACGTCACATCGATGAATTCGAGCTCGTT [32]. Correct integration of this construct was confirmed with the following: (5' left) left TGGCGTATATGGTTCATTGC; (5' right) GTATGGG CTAAATGTACGGG; (3' left) left TGGCGTATATGGT TCATTGC; (3'right) GGTTGGAGAGGCAAATTGAG.

\section{Heat shock}

Overnight cultures of S. cerevisiae were grown in $650 \mathrm{ml}$ of media at $22^{\circ} \mathrm{C}$ to between $3 \times 10^{7}$ and $1 \times 10^{8}$ cell/ 
Table 1 Strains and growth conditions

\begin{tabular}{|c|c|c|c|c|}
\hline Strain number & Species & Background & Genotype & Source \\
\hline$\overline{\mathrm{BB} 32}$ & Saccharomyces cerevisiae & & & Gift from Leonid Kruglyak's lab \\
\hline \multirow[t]{4}{*}{ BY4741 } & Saccharomyces cerevisiae & S288c & MATa, his $3 \Delta 1$, leu2 $\Delta 0$, met $15 \Delta 0$, ura $3 \Delta 0$ & Gift from Andrew Murray's lab \\
\hline & Saccharomyces cerevisiae & BY4741 & Same as above with $\operatorname{rrp} 6 \triangle:$ KANMX6 & ATCC \\
\hline & Saccharomyces cerevisiae & BY4741 & Same as above with hda2 $\triangle:: U R A 3$ & Gift from Oliver Rando's lab \\
\hline & Saccharomyces cerevisiae & BY4741 & Same as above with $\operatorname{rrp} 6 \triangle:$ :KANMX6, hda2 $\triangle::$ NatMX4 & This study \\
\hline NCYC2600 & Saccharomyces paradoxus & & & NCYC Stock Center \\
\hline IFO 1815 & Saccharomyces mikatae & & & ATCC \\
\hline CLIB 592 & Saccharomyces castellii & & & CLIB Stock Center \\
\hline CLIB 209 & Kluyveromyces lactis & & & CLIB Stock Center \\
\hline
\end{tabular}

ATCC, American Type Culture Collection.

$\mathrm{ml}, \mathrm{OD}_{600}=1.0$. The overnight culture was split into two $300 \mathrm{ml}$ cultures and cells from each were collected by removing the media via vacuum filtration (Millipore - Billerica, MA, USA). The cell-containing filters were re-suspended in pre-warmed media to either control $\left(22^{\circ} \mathrm{C}\right)$ or heat-shock temperatures $\left(37^{\circ} \mathrm{C}\right)$. Density measurements were taken approximately 1 minute after cells were re-suspended to ensure that concentrations did not change during the transfer from overnight media. We harvested $12 \mathrm{ml}$ of culture at 15 minutes and quenched by adding to $30 \mathrm{ml}$ liquid methanol at $-40^{\circ} \mathrm{C}$, which was later removed by centrifugation at $-9^{\circ} \mathrm{C}$, and stored these overnight at $-80^{\circ} \mathrm{C}$. Cell density measurements were repeatedly taken every 5 to 15 minutes for the first 2 hours after treatment. Harvested cells were later washed in RNase-free water and archived in RNAlater (Ambion - Austin, TX, USA) for future preparations. Cells were also harvested from cultures just before treatment for use as controls.

\section{Salt stress}

Overnight cultures of $S$. cerevisiae (BB32) were grown in $600 \mathrm{ml}$ of media at $30^{\circ} \mathrm{C}$ until reaching a final concentration of $3 \times 10^{7}$ and $1 \times 10^{8} \mathrm{cell} / \mathrm{ml}$. The culture was split into two parallel cultures of $250 \mathrm{ml}$ and sodium chloride was added to one culture for a final concentration of $0.3 \mathrm{M} \mathrm{NaCl}$. Cells were harvested by vacuum filtration at 15 minutes after the addition of sodium chloride and from cultures immediately before the addition of sodium chloride for use as controls $(t=0 \mathrm{~min}-$ utes). Filters were placed in liquid nitrogen and stored at $-80^{\circ} \mathrm{C}$ and were later archived in RNAlater for future use.

\section{Diauxic shift}

Overnight cultures for each species were grown to saturation in $3 \mathrm{ml}$ rich medium. From the $3 \mathrm{ml}$ overnight cultures, $300 \mathrm{ml}$ of rich media was inoculated at the $\mathrm{OD}_{600}$ corresponding to $1 \times 10^{6} \mathrm{cell} / \mathrm{ml}$ : S. cerevisiae 0.016, S. paradoxus 0.016, S. mikatae 0.023, S. bayanus
0.016, S. castellii 0.020 , and K. lactis 0.024 . The density measurements were taken approximately 1 minute after cells were re-suspended to ensure that concentrations did not change during the transfer from overnight media. Cells were harvested and quenched at a final concentration of $60 \%$ methanol at the mid-log and early stationary phase time points. Mid-log was taken at the following $\mathrm{OD}_{600}$ values: $S$. cerevisiae, $0.35 ;$ S. paradoxus, 0.40; S. mikatae, 0.40; S. bayanus, 0.30; S. castellii, 0.35; and $K$. lactis, 0.30 . The early stationary phase time points were taken 2 hours after the glucose levels reached zero. Glucose levels were monitored hourly using the YSI 2700 Select Bioanalyzer (YSI Life Sciences - Yellow Springs, OH, USA). OD 600 values for early stationary phase time points were: $S$. cerevisiae, $4.6 ; S$. paradoxus, 3.9; S. mikatae, 4.3; S. bayanus, 2.8; S. castellii, 3.2; and $K$. lactis, 5.0. Harvested cells were later washed in RNase-free water, archived in RNAlater (Ambion) for future preparations, and frozen at $-80^{\circ} \mathrm{C}$.

\section{Stationary phase}

Stationary phase was done for S. cerevisiae (BB32) only. This experiment was set up identically to the diauxic shift, but samples were taken at mid-log, and 5-day time points. The 5-day samples were taken at the same time of day as the mid-log samples.

\section{Strand-specific cDNA library}

The library was created by modifying the previously described dUTP second strand method [13]. All reagents were from Invitrogen (Carlsbad, CA, USA) except as noted. We fragmented $200 \mathrm{ng}$ of $S$. cerevisiae polyA ${ }^{+}$ RNA by heating at $98^{\circ} \mathrm{C}$ for 40 minutes in $0.2 \mathrm{mM}$ sodium citrate, pH 6.4 (Ambion). Fragmented RNA was concentrated to $5 \mu \mathrm{l}$, mixed with $3 \mu \mathrm{g}$ random hexamers, incubated at $70^{\circ} \mathrm{C}$ for 10 minutes, and placed on ice. First-strand cDNA was synthesized with this RNA primer mix by adding $4 \mu \mathrm{l}$ of $5 \times$ first-strand buffer, $2 \mu \mathrm{l}$ of $100 \mathrm{mM}$ DTT, $1 \mu \mathrm{l}$ of $10 \mathrm{mM}$ dNTPs, $4 \mu \mathrm{g}$ of actinomycin D (USB), $200 \mathrm{U}$ SuperScript III, and $20 \mathrm{U}$ 
SUPERase-In (Ambion) and incubating at room temperature for 10 minutes followed by 1 hour at $55^{\circ} \mathrm{C}$. First-strand cDNA was cleaned up by extraction twice with phenol:chloroform:isoamyl alcohol (25:24:1), followed by ethanol precipitation with 0.1 volumes $5 \mathrm{M}$ ammonia acetate to remove dNTPs and re-suspension in $104 \mu \mathrm{l} \mathrm{H}_{2} \mathrm{O}$. Second-strand cDNA was synthesized by adding $4 \mu \mathrm{l} 5 \times$ first-strand buffer, $2 \mu \mathrm{l} 100 \mathrm{mM}$ DTT, 4 $\mu \mathrm{l} 10 \mathrm{mM}$ dNTPs with dTTP replaced by dUTP (Sigma - Aldrich, St Louis, MO, USA), $30 \mu \mathrm{l} 5 \times$ second strand buffer, $40 \mathrm{U}$ Escherichia coli DNA polymerase, $10 \mathrm{U}$ E. coli DNA ligase, $2 \mathrm{U}$ E. coli $\mathrm{RNase} \mathrm{H}$ and incubating at $16^{\circ} \mathrm{C}$ for 2 hours. A paired-end library for Illumina sequencing was prepared according to the instructions provided with the following modifications. First, five times less adapter mix was ligated to the cDNAs. Second, 1 U USER (New England Biolabs - Ipswich, MA, USA) was incubated with 180 - to 480 -bp size-selected, adapter-ligated cDNA at $37^{\circ} \mathrm{C}$ for 15 minutes followed by 5 minutes at $95^{\circ} \mathrm{C}$ before PCR. Third, PCR was performed with Phusion High-Fidelity DNA Polymerase with GC buffer (New England Biolabs) and $2 \mathrm{M}$ betaine (Sigma). Fourth, PCR primers were removed using $1.8 \times$ volume of AMPure PCR Purification kit (Beckman Coulter Genomics - Danvers, MA, USA).

Strand-specific library based on the RNA ligation method The RNA ligation library was created using a previously described method [16] starting from $1.2 \mu \mathrm{g}$ of polyA ${ }^{+}$ RNA with the following modifications. RNA was fragmented by incubation at $70^{\circ} \mathrm{C}$ for 8 minutes in $1 \times$ fragmentation buffer (Ambion) and 65- to 80-nucleotide RNA fragments were isolated from a gel. RNA was reverse transcribed with SuperScript III (Invitrogen) at $55^{\circ} \mathrm{C}$ and cDNA was amplified with Herculase (Agilent Santa Clara, CA, USA) in the presence of 5\% DMSO for 16 cycles of PCR followed by a clean up with $1.8 \times$ volumes of AMPure beads (Beckman Coulter Genomics - Danvers, MA, USA) rather than gel purification.

\section{Illumina sequencing}

Both cDNA libraries were sequenced with an Illumina Genome Analyzer II (San Diego, CA, USA). The dUTP library was sequenced using 1 lane of 76-nucleotide paired reads, and the RNA ligation library was sequenced using 2 lanes of 51-nucleotide reads. All RNA-seq data are available in the Gene Expression Omnibus [GEO:GSE21739].

\section{Data pre-processing}

We used the Arachne mapper [33] to map the reads to the genome. We next identified consecutive regions of transcription by segmenting the centers of the paired- end segments with coverage $>1$ and maximum signal gaps of size 20 nucleotides.

\section{Assessment of the strand specificity of the library}

To evaluate the strand specificity of our library, we used the known annotation from SGD [14], and published estimates of UTR lengths [2], or when absent an estimation of $100 \mathrm{bp}$. According to these annotations we found that only 53,803 reads $(0.62 \%)$ mapped to the opposite strand of known transcripts.

Identification of sense and antisense transcriptional units We assigned a putative unit to a known gene if it is in the same orientation as the unit and it overlaps the known transcript boundaries, including published estimates of UTR length [2], or when absent an estimation of $100 \mathrm{bp}$ was used. When comparing our transcription units to known annotations in the SGD [14], we examined the top $85 \%$ of expressed genes, as previously described [12].

\section{Manual annotation of $\mathbf{4 0 2}$ antisense units}

We have manually annotated the boundaries of antisense units covering $75 \%$ or more of an opposite ORF, resulting in 402 antisense units covering $75 \%$ or more of 412 ORFs.

\section{Comparing the antisense units to published data from strand-specific tiling arrays}

We compared our units to the published catalog of [2] using the following criteria. For each of our units, we searched for units in the catalog of [2] that are on the same strand and overlap it. We chose the unit with the highest overlap, and required a minimal threshold of $50 \%$ overlap.

\section{Functional analysis of sense units}

We constructed a gene set from the 377 sense genes, for which at least $75 \%$ of the ORF is covered by an antisense unit, and tested it for functional enrichment using a collection of functional categories as previously described [27]. We also tested the genes for enriched induction or repression in a compendium of 1,400 annotated arrays, as previously described [27].

\section{Identification of candidate regions in other species}

We searched for orthologs of the sense gene in other species, using our published orthogroup catalog [27], and used the relative coordinates of the antisense transcripts in S. cerevisiae relative to the sense gene to predict their locations in other species. In cases where there were no clear candidates for orthologs, or the synteny block was broken [26], we did not define a candidate. 


\section{Strand-specific RT-PCR}

Strand-specific RT-PCR followed an adaptation of a published protocol [34]. Total RNA was isolated from strain $\mathrm{Bb} 32(3)$ at late log time point for two biological replicates. RNA was Turbo DNase treated (Ambion) following the manufacturer's stringent protocol followed by phenol chloroform extraction. For each assay, a gene-specific, strand-specific reverse transcription (RT) was performed. The four reactions for each sample were: +RT L-primer (sense), +RT R-Primer (antisense), $+\mathrm{RT}$ no primer, $-\mathrm{RT}$ both primers. First strand cDNA synthesis started RNA denaturation and the hybridization of the 2 pmol of gene specific primer. Total RNA with primer $(10 \mathrm{ng})$ was heated to $70^{\circ} \mathrm{C}$ for 10 minutes and incubated on ice for at least 1 minute. A primer targeting ACT1 mRNA was always included as an internal control for strand specificity. This was followed by adding a Master mix containing 200 U SuperScript III (Invitrogen), $40 \mathrm{U}$ RNaseOut (Invitrogen) and $10 \mathrm{mM}$ dNTP mix for at $55^{\circ} \mathrm{C}$ for 15 minutes. The enzyme was heatinactivated at $70^{\circ} \mathrm{C}$ for 15 minutes. RNA complementary to the cDNA was removed by E. coli RNase H (10 U; Ambion) and remaining RNAs were digested with $20 \mathrm{U}$ of RNase Cocktail (Ambion) by incubating at $37^{\circ} \mathrm{C}$ for 20 minutes. PCR was performed for the sense and antisense transcripts independently. We added $5 \mu \mathrm{l}$ of RT to each reaction as template with two gene-specific primers each at $250 \mathrm{nM}$ final concentration (the same primers that were used for the sense and antisense RT; Additional file 7), $300 \mu \mathrm{M} d N T P$ and $1 \mathrm{U}$ of Ampli Taq Gold (Applied Biosystems - Carlsbad, CA, USA), in a 50 $\mu \mathrm{l}$ reaction. RNA contaminated with genomic DNA was used as a positive control. The touch down amplification program used was as follows: incubation of $95^{\circ} \mathrm{C}$ for 5 minutes followed by 10 cycles of $95^{\circ} \mathrm{C}$ for $30 \mathrm{~s}, 60^{\circ} \mathrm{C}$ for $30 \mathrm{~s}-1$ degree per cycle, $70^{\circ} \mathrm{C}$ for $45 \mathrm{~s}$, then followed by 17 to 20 cycles of $95^{\circ} \mathrm{C}$ for $30 \mathrm{~s}, 50^{\circ} \mathrm{C}$ for $30 \mathrm{~s}, 70^{\circ} \mathrm{C}$ $45 \mathrm{~s}, 72^{\circ} \mathrm{C}$ for 10 minutes (a step required for future Topo TA cloning (Invitrogen)).

\section{Strand-specific RT-PCR across species}

Strand-specific RT-PCR across species used an adaptation of a published protocol [35]. Total RNA was isolated from each species at both the mid-log and early stationary phase time points. Genomic DNA contamination was removed with Turbo DNase (Ambion) using the stringent protocol, and phenol:chloroform to extract the RNA and to inactivate the DNase. For each of the species two biological replicates of the mid-log and early stationary phase time points were tested. Four reactions were performed for each sample: $+\mathrm{RT}$ L-primer (sense), $+\mathrm{RT}$ R-primer (antisense), +RT no primer, $-\mathrm{RT}$. The sense, antisense, and - RT reactions were done with 2 pmol of primer (Additional file 7; only the primers with A1 in the title were used for the initial RT-PCR, and all primers used were designed for the target species). RT was done with first strand synthesis only in 20- $\mu$ l reactions, using 4 units of Omniscript reverse transcriptase (Qiagen - Valencia, CA, USA) and $500 \mathrm{ng}$ of total RNA. Each reaction was carried out at $50^{\circ} \mathrm{C}$ for 20 minutes, and heat inactivated at $70^{\circ} \mathrm{C}$ for 15 minutes. PCR was conducted as for the $S$. cerevisiae RT-PCR described above.

\section{Strand-specific qRT-PCR across species}

The same RT protocol was followed for the qRT-PCR across species as for the RT PCR above. For each senseantisense pair validated, two sets of primers were tested, and primers for two internal control genes $(A C T 1$ and $P D A 1)$ were included in each reaction. Control primers ('right primer', Additional file 7) were added at a concentration of 2 pmol to each of the RT reactions. qPCR was done using the Roche Light Cycler 480 in 12- $\mu$ l reactions in a 384 well plate (Roche - Indianapolis, IN, USA). qPCR was done independently for sense, antisense, and control genes. RT samples were diluted 1:40 in water then 1:2 in Light Cycler 480 SYBR Green I Master with gene specific primer pair (each primer at $200 \mathrm{nM}$ final concentration). The program protocol used was as follows: activation, $95^{\circ} \mathrm{C}$ for 5 minutes; cycling, $95^{\circ} \mathrm{C}$ for $15 \mathrm{~s}$ and $60^{\circ} \mathrm{C}$ for $45 \mathrm{~s}$; melt, $95^{\circ} \mathrm{C}$ continuous.

\section{Analysis of strand-specific qRT-PCR data}

The ratios reported in Additional file 5 and Figure 2a are $\log _{2}$ ratios of early stationary phase and mid-log qRT-PCR reads (after normalization by the control gene $P D A 1)$, averaged over the two sets of primers and the two biological repeats.

\section{nCounter measurements}

The following experiments were done in biological duplicates: heat shock - 0 and 15 minutes; salt stress - 0 and 15 minutes; diauxic shift - log and early stationary phase; and stationary phase - $\log$ and 5 days. Details on the nCounter system are presented in full in [20]. In a nutshell, the nCounter system uses pre-defined probes labeled with molecular barcodes ('code sets') and single molecule imaging to detect and directly count millions of unique transcripts (from up to hundreds of genes) in a single reaction. The assay is performed in cell lysates, involves no enzymatic steps prior to detection, and is highly accurate. Code sets were constructed to detect putative antisense units and sense genes and additional controls (Additional file 8). We lysed $7 \times 10^{7}$ (or $2 \times$ $10^{7}$, depending on the code set) cells according to the RNeasy (Qiagen) yeast mechanical lysis protocol. The protocol was stopped after spinning the lysate to remove 
debris, and $3 \mu \mathrm{l}$ of the lysate was hybridized for 16 hours followed by processing in the nCounter Prep Station and quantification by the nCounter Digital Analyzer. We normalized the nCounter data in two steps as previously described [19]. In the first step, we controlled for small variations in the efficiency of the automated sample processing. To this end, we followed the manufacturer's instructions, and normalized measurements from all samples analyzed on a given run to the levels of a chosen sample (in all cases we used the first sample in the set). This was done using the positive spiked-in controls provided by the nCounter instrument. In the second step, we used the control genes for which we designed probes to normalize for sample variation.

\section{Additional material}

Additional file 1: Table S1. Strand-specific (sense and antisense)

transcribed units in mid-log $S$. cerevisiae.

Additional file 2: Table S2. Sense and antisense coverage of SGD annotated genes.

Additional file 3: Figure S1 to S9. Figure S1: read coverage at antisense units. (a,b) The distribution (a) and cumulative distribution (CDF) (b) of read coverage at antisense units 'called' by our method (gray) and at all other loci in the genome with at least one antisense read (orange). The called units have substantially deeper coverage, whereas $80 \%$ of sporadic loci are covered by a single read. (c) Sense coverage ( $x$-axis) versus antisense coverage ( $y$-axis) of all verified genes. Genes that we have detected antisense units opposite them are shown in orange. Figure S2: statistics for transcription units. (a) Distribution of antisense unit length, colored by the percentage of overlap with the opposite ORF. Dark blue, units with at least $25 \%$ overlap with the opposite transcript; light blue, units with at least 50\% overlap with the opposite ORF; green, units with at least $75 \%$ overlap with the opposite ORF; orange, units with 100\% overlap with the opposite ORF. (b) Cumulative distribution function of the units length. Blue, antisense units; red, other units. Figure S3: an example of an over-segmented antisense unit. Shown is the genomic region of OPT2; tracks and colors are as in Figure 1, with the addition of the brown tracks showing the centers of the paired end segments (forward and reverse), which were used for the segmentation (Materials and methods). All coverage tracks are normalized and shown up to a threshold of $3 \times 10^{-8}$ of the total (genome-wide) number of mapped reads. Due to low read coverage, both the sense (blue) and the antisense units (yellow) are over-segmented. After the manual curation of the antisense units, we defined one long antisense unit (ManualUnit402) that covers the entire ORF of the gene OPT2. The figure is shown using the Integrative Genome Viewer [36]. Figure S4: promoter types associated with antisense units. Shown are two examples of promoter types of antisense units; tracks and colors as in Figure 1. ManualUnit69 included the $B T T 1$ gene, and a very long $3^{\prime}$ UTR, as an antisense to the gene MET32. ManualUnit70 is a long antisense to the gene CTA1, and is transcribed from the divergent promoter of RMD5. The figures are shown using the Integrative Genome Viewer [36]. Figure S5: correlation between differential expression of antisense units and their neighboring (nonoverlapping) genes. Expression of antisense units versus neighboring genes, which could be co-regulated (using published tiling array data [2]). Shown is the log ratio of change from glucose (YPD) to ethanol (YPE). Blue, antisense units with shared promoter (as in Figure S3 in Additional file 3); red, antisense units with a nearby 3' UTR; green, linear fit. Figure S6: differences in UTR length between genes with nearby antisense units, compared to all genes. Cumulative distribution of the UTR lengths of all genes (blue) and those with antisense units ending close to the 3' UTR end. Figure S7: differential expression of antisense units and their target sense transcripts. (a) Expression of sense versus antisense units (using published tiling array data [2]). Shown is the log ratio of change in sense gene expression from YPD to YPE ( $x$-axis) plotted versus the same for the antisense strand (y-axis). Red, differentially expressed genes; green, linear fit. $(\mathbf{b}, \mathbf{c})$ The same as (a), only comparing YPD to galactose growth and to an rrp6 deletion mutant, respectively. Figure S8: mutant effect on transcription. (a-c) Expression changes of the sense genes ( $x$-axis) versus expression changes of the antisense units (y-axis) in the $\Delta r r p 6$ mutant (a), the $\Delta h d a 2$ mutant (b), and the $\Delta r r p 6 \Delta h d a 2$ mutant (c). Figure S9: mutant effect on differential expression. (a-c) Differential expression of the sense genes from mid-log to early stationary phase in the wild type (x-axis) versus the $\Delta r r p 6$ mutant (a), the $\Delta h d a 2$ mutant (b), and the $\Delta r r p 6 \Delta h d a 2$ mutant (c).

Additional file 4: Table S3. Antisense units validated in RT experiments in S. cerevisiae.

Additional file 5: Table S4. qRT-PCR results in each gene and species.

Additional file 6: Table S5. Nanostring results in S. cerevisiae.

Additional file 7: Table S6. RT and QRT-PCR primers in each gene and species.

Additional file 8: Table S7. Control genes used for the Nanostring nCounter assays.

\section{Abbreviations}

bp: base pair; DTT: dithiothreitol; NFR: nucleosome-free region; ORF: open reading frame; QRT-PCR: quantitative reverse transcriptase PCR; RNA-seq: RNA sequencing; SGD: Saccharomyces Genome Database; UTR: untranslated region; WGD: whole genome duplication; YPD: yeast peptone dextrose; YPE: yeast peptone ethanol.

\section{Acknowledgements}

MY was supported by the Canadian Friends of the Hebrew University. The work was supported by the Howard Hughes Medical Institute, the Human Frontiers Science Program, a Career Award at the Scientific Interface from the Burroughs Welcome Fund, an NIH PIONEER award, the Broad Institute, and a Sloan Fellowship (AR), the National Human Genome Research Institute (NHGRI) (CN), and by a US-Israel Bi-national Science Foundation award (NF and MY).

\section{Author details}

${ }^{1}$ Broad Institute of MIT and Harvard, 7 Cambridge Center, Cambridge, MA 02142, USA. ${ }^{2}$ Howard Hughes Medical Institute, Department of Biology, Massachusetts Institute of Technology, 31 Ames Street, 68-132, Cambridge, MA 02139, USA. ${ }^{3}$ School of Engineering and Computer Science, Hebrew University, Ross Building, Givat Ram Campus, Jerusalem, 91904, Israel. ${ }^{4}$ Alexander Silberman Institute of Life Sciences, Hebrew University, Edmond J Safra Campus, Givat Ram, Jerusalem, 91904, Israel.

\section{Authors' contributions}

$M Y, J P, J Z L, A G, C N, D-A T, N F$, and AR designed the research; MY, JP, JZL, XA, $D-A T, N F$, and AR performed research; MY, NF, and AR analyzed data; JZL and $\mathrm{XA}$ contributed text to the methods section; and MY, NF, and AR wrote the paper with editorial input from all authors. All authors read and approved the final manuscript.

Received: 15 February 2010 Revised: 26 July 2010

Accepted: 26 August 2010 Published: 26 August 2010

\section{References}

1. Faghihi MA, Wahlestedt C: Regulatory roles of natural antisense transcripts. Nat Rev Mol Cell Biol 2009, 10:637-643.

2. Xu Z, Wei W, Gagneur J, Perocchi F, Clauder-Münster S, Camblong J, Guffanti E, Stutz F, Huber W, Steinmetz LM: Bidirectional promoters generate pervasive transcription in yeast. Nature 2009, 457:1033-1037.

3. Neil H, Malabat C, d'Aubenton-Carafa Y, Xu Z, Steinmetz LM, Jacquier A: Widespread bidirectional promoters are the major source of cryptic transcripts in yeast. Nature 2009, 457:1038-1042.

4. Wilhelm BT, Marguerat S, Watt S, Schubert F, Wood V, Goodhead I, Penkett CJ, Rogers J, Bahler J: Dynamic repertoire of a eukaryotic 
transcriptome surveyed at single-nucleotide resolution. Nature 2008, 453:1239-1243.

5. Dutrow N, Nix DA, Holt D, Milash B, Dalley B, Westbroek E, Parnell TJ, Cairns BR: Dynamic transcriptome of Schizosaccharomyces pombe shown by RNA-DNA hybrid mapping. Nat Genet 2008, 40:977-986.

6. Hongay, Grisafi, Galitski, Fink : Antisense transcription controls cell fate in Saccharomyces cerevisiae. Cell 2006, 127:735-745.

7. Camblong J, Iglesias, Fickentscher, Dieppois, Stutz : Antisense RNA stabilization induces transcriptional gene silencing via histone deacetylation in S. cerevisiae. Cell 2007, 131:706-717.

8. Houseley, Rubbi, Grunstein, Tollervey, Vogelauer : A ncRNA modulates histone modification and mRNA induction in the yeast GAL gene cluster. Mol Cell 2008, 32:685-695.

9. Nishizawa, Komai, Katou, Shirahige, Ito, Toh-E : Nutrient-regulated antisense and intragenic RNAs modulate a signal transduction pathway in yeast. PLOS Biol 2008, 6:2817-2830.

10. Nagalakshmi U, Wang Z, Waern K, Shou C, Raha D, Gerstein M, Snyder M: The transcriptional landscape of the yeast genome defined by RNA sequencing. Science 2008, 320:1344-1349.

11. Mortazavi A, Williams BA, McCue K, Schaeffer L, Wold B: Mapping and quantifying mammalian transcriptomes by RNA-Seq. Nat Methods 2008, 5:621-628.

12. Yassour M, Kaplan T, Fraser HB, Levin JZ, Pfiffner J, Adiconis X, Schroth G, Luo S, Khrebtukova I, Gnirke A, Nusbaum C, Thompson DA, Friedman N, Regev A: Ab initio construction of a eukaryotic transcriptome by massively parallel mRNA sequencing. Proc Natl Acad Sci USA 2009, 106:3264-3269.

13. Parkhomchuk D, Borodina T, Amstislavskiy V, Banaru M, Hallen L, Krobitsch S, Lehrach H, Soldatov A: Transcriptome analysis by strandspecific sequencing of complementary DNA. Nucleic Acids Res 2009, 37: e123.

14. Cherry JM, Adler C, Ball C, Chervitz SA, Dwight SS, Hester ET, Jia Y, Juvik G, Roe T, Schroeder M, Weng S, Botstein D: SGD: Saccharomyces Genome Database. Nucleic Acids Res 1998, 26:73-79.

15. Levin JZ, Yassour M, Adiconis X, Nusbaum C, Thompson DA, Friedman N, Gnirke A, Regev A: Comprehensive comparative analysis of strandspecific RNA sequencing methods. Nat Methods 2010.

16. Lister R, O'Malley RC, Tonti-Filippini J, Gregory BD, Berry CC, Millar AH, Ecker JR: Highly integrated single-base resolution maps of the epigenome in Arabidopsis. Cell 2008, 133:523-536.

17. Berretta J, Morillon A: Pervasive transcription constitutes a new level of eukaryotic genome regulation. EMBO Rep 2009, 10:973-982.

18. Tsankov A, Thompson DA, Socha A, Regev A, Rando OJ: The role of nucleosome positioning in the evolution of gene regulation. PLOS Biol 2010, 8:e1000414.

19. Amit I, Garber M, Chevrier N, Leite AP, Donner $Y$, Eisenhaure T, Guttman M, Grenier JK, Li W, Zuk O, Schubert LA, Birditt B, Shay T, Goren A, Zhang X, Smith Z, Deering R, McDonald RC, Cabili M, Bernstein BE, Rinn JL, Meissner A, Root DE, Hacohen N, Regev A: Unbiased reconstruction of a mammalian transcriptional network mediating pathogen responses. Science 2009, 326:257-263.

20. Geiss GK, Bumgarner RE, Birditt B, Dahl T, Dowidar N, Dunaway DL, Fell HP, Ferree S, George RD, Grogan T, James JJ, Maysuria M, Mitton JD, Oliveri P, Osborn JL, Peng T, Ratcliffe AL, Webster PJ, Davidson EH, Hood L, Dimitrov K: Direct multiplexed measurement of gene expression with color-coded probe pairs. Nat Biotechnol 2008, 26:317-325.

21. Brown MP, Grundy WN, Lin D, Cristianini N, Sugnet CW, Furey TS, Ares M Jr. Haussler D: Knowledge-based analysis of microarray gene expression data by using support vector machines. Proc Natl Acad Sci USA 2000, 97:262-267.

22. Reisdorf P, Boy-Marcotte E, Bolotin-Fukuhara M: The MBR1 gene from Saccharomyces cerevisiae is activated by and required for growth under sub-optimal conditions. Mol Gen Genet 1997, 255:400-409.

23. Martin DE, Soulard A, Hall MN: TOR regulates ribosomal protein gene expression via PKA and the Forkhead transcription factor FHL1. Cell 2004, 119:969-979.

24. Agarwal S, Sharma S, Agrawal V, Roy N: Caloric restriction augments ROS defense in $S$. cerevisiae, by a Sir2p independent mechanism. Free Radic Res 2005, 39:55-62.
25. Chechik G, Oh E, Rando O, Weissman J, Regev A, Koller D: Activity motifs reveal principles of timing in transcriptional control of the yeast metabolic network. Nat Biotechnol 2008, 26:1251-1259.

26. Byrne KP, Wolfe KH: Visualizing syntenic relationships among the hemiascomycetes with the Yeast Gene Order Browser. Nucleic Acids Res 2006, 34:D452-455.

27. Wapinski I, Pfeffer A, Friedman N, Regev A: Natural history and evolutionary principles of gene duplication in fungi. Nature 2007, 449:54-61.

28. He Y, Vogelstein B, Velculescu VE, Papadopoulos N, Kinzler KW: The antisense transcriptomes of human cells. Science 2008, 322:1855-1857.

29. Guttman M, Amit I, Garber M, French C, Lin MF, Feldser D, Huarte M, Zuk O, Carey BW, Cassady JP, Cabili MN, Jaenisch R, Mikkelsen TS, Jacks T, Hacohen N, Bernstein BE, Kellis M, Regev A, Rinn JL, Lander ES: Chromatin signature reveals over a thousand highly conserved large non-coding RNAs in mammals. Nature 2009, 458:223-227.

30. Drinnenberg IA, Weinberg DE, Xie KT, Mower JP, Wolfe KH, Fink GR, Bartel DP: RNAi in budding yeast. Science 2009, 326:544-550.

31. Supplementary Website. [http://compbio.cs.huji.ac.il/YeastAntisense].

32. Goldstein AL, McCusker JH: Three new dominant drug resistance cassettes for gene disruption in Saccharomyces cerevisiae. Yeast 1999, 15:1541-1553.

33. Batzoglou S, Jaffe DB, Stanley K, Butler J, Gnerre S, Mauceli E, Berger B, Mesirov JP, Lander ES: ARACHNE: a whole-genome shotgun assembler. Genome Res 2002, 12:177-189.

34. Perocchi F, Xu Z, Clauder-Munster S, Steinmetz LM: Antisense artifacts in transcriptome microarray experiments are resolved by actinomycin $\mathrm{D}$. Nucleic Acids Res 2007, 35:e128.

35. Haddad F, Qin AX, Giger JM, Guo H, Baldwin KM: Potential pitfalls in the accuracy of analysis of natural sense-antisense RNA pairs by reverse transcription-PCR. BMC Biotechnol 2007, 7:21.

36. Integrative Genomics Viewer. [http://www.broadinstitute.org/igv].

\section{doi:10.1186/gb-2010-11-8-r87}

Cite this article as: Yassour et al:: Strand-specific RNA sequencing reveals extensive regulated long antisense transcripts that are conserved across yeast species. Genome Biology 2010 11:R87.

\section{Submit your next manuscript to BioMed Central and take full advantage of:}

- Convenient online submission

- Thorough peer review

- No space constraints or color figure charges

- Immediate publication on acceptance

- Inclusion in PubMed, CAS, Scopus and Google Scholar

- Research which is freely available for redistribution

Submit your manuscript at www.biomedcentral.com/submit
C Biomed Central 